\title{
Influence of microstructure and crystalline phases on impedance spectra of sodium conducting glass ceramics produced from glass powder
}

\author{
Mihails Kusnezoff $^{1}\left[\right.$ [D $\cdot$ Dörte Wagner $^{1} \cdot$ Jochen Schilm $^{1} \cdot$ Christian Heubner $^{1} \cdot$ Björn Matthey $^{1} \cdot$ Chang Woo Lee $^{2}$
}

Received: 2 July 2021 / Revised: 25 September 2021 / Accepted: 6 October 2021 / Published online: 20 October 2021

(c) The Author(s) 2021

\begin{abstract}
Crystallization of highly ionic conductive $\mathrm{N} 5\left(\mathrm{Na}_{5} \mathrm{YSi}_{4} \mathrm{O}_{12}\right)$ phase from melted $\mathrm{Na}_{3+3 \mathrm{x}-1} \mathrm{Y}_{1-\mathrm{x}} \mathrm{P}_{\mathrm{y}} \mathrm{Si}_{3-\mathrm{y}} \mathrm{O}_{9}$ parent glass provides an attractive pathway for cost-effective manufacturing of Na-ion conducting thin electrolyte substrates. The temperaturedependent crystallization of parent glass results in several crystalline phases in the microstructure $\left(\mathrm{N} 3\left(\mathrm{Na}_{3} \mathrm{YSi}_{2} \mathrm{O}_{7}\right), \mathrm{N} 5\right.$ and $\mathrm{N} 8$ (Na8.1Y Si6O18) phases) as well as in rest glass phase with temperature dependent viscosity. The electrical properties of dense parent glass and of compositions densified and crystallized at $700{ }^{\circ} \mathrm{C}, 800{ }^{\circ} \mathrm{C}, 900{ }^{\circ} \mathrm{C}, 1000{ }^{\circ} \mathrm{C}$, and $1100{ }^{\circ} \mathrm{C}$ are investigated by impedance spectroscopy and linked to their microstructure and crystalline phase content determined by Rietveld refinement. The parent glass has high isolation resistance and predominantly electrons as charge carriers. For sintering at $\geq 900{ }^{\circ} \mathrm{C}$, sufficient N5 phase content is formed to exceed the percolation limit and form ion-conducting pathways. At the same time, the highest content of crystalline phase and the lowest grain boundary resistance are observed. Further increase of the sintering temperature leads to a decrease of the grain resistance and an increase of grain boundary resistance. The grain boundary resistance increases remarkably for samples sintered at $1100{ }^{\circ} \mathrm{C}$ due to softening of the residual glass phase and wetting of the grain boundaries. The conductivity of fully crystallized N5 phase (grain conductivity) is calculated from thorough impedance spectra analysis using its volume content estimated from Rietveld analysis, density measurements and assuming reasonable tortuosity to $2.810^{-3} \mathrm{~S} \mathrm{~cm}^{-1}$ at room temperature. The excellent conductivity and easy processing demonstrate the great potential for the use of this phase in the preparation of solid-state sodium electrolytes.
\end{abstract}

Keywords Solid electrolyte $\cdot$ Ionic conductivity $\cdot$ Impedance spectroscopy $\cdot$ Sodium battery

\section{Introduction}

Solid-state batteries (SSBs) operating at ambient temperature are considered as a key enabling technology for next generation electrical storage devices [1]. Whereas Li-ion

Mihails Kusnezoff

mihails.kusnezoff@ikts.fraunhofer.de

Chang Woo Lee

cwlee@khu.ac.kr

1 Fraunhofer Institute for Ceramic Technology and Systems Fraunhofer IKTS, Winterbergstrasse 28, 01277 Dresden, Germany

2 Department of Chemical Engineering (Integrated Engineering) \& Center for the SMART Energy Platform, College of Engineering, Kyung Hee University, 1732 Deogyeong-daero, Giheung, Gyeonggi 17104 Yongin, South Korea batteries (LIBs) address mobile and stationary storage, the $\mathrm{Na}$-ion batteries (SIBs) are historically focused on stationary applications, successfully competing with lithium technology on 10-40 MWh scale [2]. The industrialization of LIBs raises many concerns connected with availability and costs of raw material and abundance of $\mathrm{Li}$ and $\mathrm{Co}$ in amounts needed for sustainable worldwide production cycle [3, 4]. Therefore, sodium electrochemistry reattracts increasing attention in academia and industry due to unrestricted access and availability of raw materials worldwide.

The successful development of LIBs with liquid electrolytes increased attention to the development of room temperature sodium batteries [3]. The tetraethylene glycol dimethyl ether (TEGDME) with $\mathrm{NaCF}_{3} \mathrm{SO}_{3}$ as conducting salt [5] and dimethoxyethane (DME) and/or TEGDME solutions have been developed and increasingly used for SIBs because of relatively high flash point, poor flammability and wide electrochemical stability window [6-8]. Meanwhile, 
carbonate-based electrolytes like in EC/DMC or EC/PC with solved $\mathrm{NaPF}_{6}$ or $\mathrm{NaClO}_{4}$ salt are also applied in sodium room temperature batteries [9-11]. The progress of SIBs utilizing liquid electrolytes is however hindered by dendrite formation (intercalation batteries) /polysulfide shuttle mechanism (room temperature Na-S battery) during charging/discharging, which is more severe in comparison to lithium electrochemistry [3]. For this reason, the multiple approaches for development of $\mathrm{Na}$ ion conducting solid-state electrolytes for room temperature SSBs have been attempted.

The solid electrolyte is the core component of SSBs and is a topic of intensive explorative and fundamental research. The main goals of research activities are focused on improvement of its ionic conductivity, manufacturing and processing technology as well as understanding of transport phenomena and interfacial reactions $[12,13]$. Both Liand Na-based SSB would strongly benefit from possibility of utilization of metal anodes to boost the energy density [14-16]. Therefore, scientists are looking for stable electrolyte materials that enable a wide electrochemical window. Furthermore, the dendrite formation as the largest challenge for the cycle life of LIBs [17] and especially SIBs [4] is strongly diminished, if a solid electrolyte is used [14]. Only few classes of materials meet these requirements and utilized as $\mathrm{Na}$ ion conducting electrolytes at room temperature.

Similar to LIBs, four classes of solid electrolyte materials are in competition for boosting SIB performance: polymers, oxides (including phosphates), sulfides, and boranes [14]. While polymer electrolytes in lithium-based solid-state batteries are already established on an industrial level (Boloré), sodium-based concepts have only been investigated by initial approaches. The high ionic conductivities at room temperature were reported for $\mathrm{Na}_{2}\left(\mathrm{CB}_{9} \mathrm{H}_{10}\right)\left(\mathrm{CB}_{11} \mathrm{H}_{12}\right)(60$ $\mathrm{mS} / \mathrm{cm}$ ) [18], $\mathrm{Na}_{2.88} \mathrm{Sb}_{0.88} \mathrm{~W}_{0.12} \mathrm{~S}_{4}$ (16-32 $\mathrm{mS} / \mathrm{cm}$ depending on the applied compression in the cell) [19], Na- $/ / \beta$ "$\mathrm{Al}_{2} \mathrm{O}_{3}(6.1 \mathrm{mS} / \mathrm{cm})$ [20], $\mathrm{Na}_{3.4} \mathrm{Zr}_{2} \mathrm{Si}_{2.4} \mathrm{P}_{0.6} \mathrm{O}_{12}(4.8 \mathrm{mS} /$ cm) [21], $\mathrm{Na}_{5} \mathrm{YSi}_{4} \mathrm{O}_{12}(1.5 \mathrm{mS} / \mathrm{cm})$ [22], and the polymer PEO:SN:NaCF3SO3 (6:3:1) $(0.1 \mathrm{mS} / \mathrm{cm})$ [23].

In particular, oxides/phosphates are considered suitable to suppress dendrite growth and exhibit high electrochemical stability [24]. Na-ion conductors offer the broadest choice of oxide/phosphate materials, which can be utilized as electrolytes in sodium metal based SSBs. The most prominent representatives of $\mathrm{Na}$-conducting electrolytes are $\mathrm{Na}-\mathrm{\beta}$ ' '$\mathrm{Al}_{2} \mathrm{O}_{3}$ and $\mathrm{Na}_{1,3} \mathrm{Zr}_{2}\left(\mathrm{SiO}_{4}\right)_{0,3}\left(\mathrm{PO}_{4}\right)_{2,7}$ with reported ionic conductivities at $25^{\circ} \mathrm{C}$ of $1-1.5 \mathrm{mS} \mathrm{cm}{ }^{-1}\left(\mathrm{Na}_{\mathrm{x}} \mathrm{Al}_{11-\mathrm{x} / 3} \mathrm{O}_{17}\right.$ with $1 \leq x<1.7$ ) [25] and $0.1-1 \mathrm{mS} \mathrm{cm}^{-1}$ [26], respectively. In the $\mathrm{R}_{2} \mathrm{O}_{3}-\mathrm{Na}_{2} \mathrm{O}-\mathrm{SiO}_{2}$-system $(\mathrm{R}=\mathrm{Sc}, \mathrm{Y}, \mathrm{Sm}, \mathrm{Gd}, \mathrm{Yb})$, a hardly studied class of sodium conducting compositions exists, firstly reported by Shannon et al. [27]. Especially, incorporation of yttrium as a rare earth element resulted in high ionic conductivity of $0.2 \mathrm{~S} \mathrm{~cm}^{-1}\left(300{ }^{\circ} \mathrm{C}\right)$ [27]. In particular, the composition $\mathrm{Na}_{5} \mathrm{YSi}_{4} \mathrm{O}_{12}$ (so-called $\mathrm{N} 5$ phase) shows a high ionic conductivity of $1 \mathrm{mS} \mathrm{cm}^{-1}$ at room temperature, which is attractive for application in SSBs. Different routes for the synthesis of sodium conducting compositions in this system have been investigated to optimize ionic conductivity [28]. In every case, it was found that suitable compositions can undergo complex phase transformations within the synthesis process starting from the parental raw materials (glasses or other precursors) and resulting in $\mathrm{N} 5\left(\mathrm{Na}_{5} \mathrm{YSi}_{4} \mathrm{O}_{12}\right), \mathrm{N} 3$ $\left(\mathrm{Na}_{3} \mathrm{YSi}_{2} \mathrm{O}_{7}\right)$, and $\mathrm{N} 1\left(\mathrm{NaYSiO}_{4}\right)$ crystalline phases. Since 1985, Yamashita's group investigates the manufacturing and properties of $\mathrm{Na}_{5} \mathrm{YSi}_{4} \mathrm{O}_{12}$-based electrolytes [29]. The work is focused on the crystallization of parental glasses with compositions similar to the N3-type with different stoichiometric variations according to the general formula $\mathrm{Na}_{3+3 x-1} \mathrm{Y}_{1-x} \mathrm{P}_{y} \mathrm{Si}_{3-y} \mathrm{O}_{9}$ aiming at the crystallization of the highly conducting N5-type [30]. The addition of $\mathrm{P}_{2} \mathrm{O}_{5}$ stabilizes the synthesized glass structure and supports controlling the crystallization of the ionically well conducting N5 phase and also poor conducting $\mathrm{N} 3$ and $\mathrm{N} 9\left(\mathrm{Na}_{9} \mathrm{YSi}_{6} \mathrm{O}_{18}\right)$ phases. By tuning $\mathrm{Na}_{3+3 x-1} \mathrm{Y}_{1-x} \mathrm{P}_{y} \mathrm{Si}_{3-y} \mathrm{O}_{9}$ composition, the amount of conductive N5 phase has been increased [31]. Finally, Okura et al. [32] demonstrated the crystallization of $\mathrm{N} 5$ phase from quenched glass samples with proper $\mathrm{Na}_{3+3 x-y} \mathrm{Y}_{1-x} \mathrm{P}_{y} \mathrm{Si}_{3-y} \mathrm{O}_{9}$ (NAPSY) stoichiometry by annealing at $500{ }^{\circ} \mathrm{C}$ for $3 \mathrm{~h}$, preseeding step at $50{ }^{\circ} \mathrm{C}$ above the glass transition temperature $\left(\mathrm{T}_{\mathrm{g}}\right.$ ), and crystallization step at $800-1000{ }^{\circ} \mathrm{C}$. The presence of an additional $\mathrm{N} 8\left(\mathrm{Na}_{8.1} \mathrm{YSi}_{6} \mathrm{O}_{18}\right)$ phase during the crystallization process was observed, which disappears during re-crystallization process at higher temperatures and thus acts as a precursor phase for N5 phase formation. Despite the crystallization ability of high content of N5 phase, the total conductivity of $0.066 \mathrm{~S} \mathrm{~cm}^{-1}$ at $300{ }^{\circ} \mathrm{C}$ has been achieved due to the presence of $\mathrm{N} 3$ and $\mathrm{N} 9$ isolating rest phases, having ionic conductivity 1 to 3 orders of magnitude higher than the N5 target phase [33]. A recently published review article by Okura and Yamashita [28] gives a comprehensive overview of the current developments of this class of sodium-ion super conductors and highlights the possibilities of producing solid electrolyte components by crystallization of bulk glass samples.

Another manufacturing route has been proposed by authors of this paper [34], who succeeded in manufacturing electrolyte substrates from glass frit with nominal composition close to $\mathrm{Na}_{5} \mathrm{YSi}_{4} \mathrm{O}_{12}$. It was found that the addition of phosphorous acid allows the separation of the sintering and crystallization processes enabling a cost-effective single step sintering and crystallization process. The reported crystalline phase evolution was in good agreement with results reported by Okura et al. [32]. Despite promising progress in electrolyte preparation and selective phase crystallization, crucial relationships between ionic conductivity, and the degree of crystallization and recrystallization, as well as the presence of a residual glass phase, are not yet understood 
in detail. The present work aims to contribute to the understanding of these relationships to support the knowledgebased development process.

\section{Experimental}

The method of sintering and crystallization of powder compacts based on suitable glass powders was used for the preparation of the solid electrolyte samples. The raw materials as silicon oxide (Millisil W8, Quarzwerke Frechen, Germany), yttrium oxide $\left(\mathrm{Y}_{2} \mathrm{O}_{3}\right.$ Grade C, H.C. Starck, Germany), and sodium carbonate (AnalaR NORMAPUR, VWR) are dry tumble mixed for $30 \mathrm{~min}$ in stoichiometry of $\mathrm{Na}_{5} \mathrm{YSi}_{4} \mathrm{O}_{12}$. Then, the components are mixed with phosphorous acid (ortho-phosphoric acid 85\%, Carl Roth) in an alumina crucible and slowly calcined $\left(1 \mathrm{~K} \mathrm{~min}^{-1}\right)$ held for $1 \mathrm{~h}$ at $500{ }^{\circ} \mathrm{C}$. Finally, the mixture was molten at $1450{ }^{\circ} \mathrm{C}$ in a platinum-rhodium-crucible (90/10) and finally quenched on a brass block resulting in a glass frit. The milling step was performed for $12 \mathrm{~h}$ in a planetary micromill (Pulverisette 7, Fritsch, Germany) with milling balls and cups made of zirconia.

The average particle size was determined with laser diffraction in a particle size range between $20 \mathrm{~nm}$ and $2000 \mu \mathrm{m}$ (Mastersizer 2000, Malvern Instruments Ltd.). The characteristic particle sizes of the glass powder after milling were for $\mathrm{d}_{10}=1.2 \mu \mathrm{m}$, for $\mathrm{d}_{50}=5.8 \mu \mathrm{m}$ and for $\mathrm{d}_{90}=25.8 \mu \mathrm{m}$. The milled powder is used for the single-step preparation of the glass-ceramic samples. Amounts of around $10 \mathrm{mg}$ powder were pressed by isostatic press to cylindrical pellets of diameter $6 \mathrm{~mm}$ and thickness $5.7-6.3 \mathrm{~mm}$. The sintering of pellets was done under ambient atmosphere on a platinum foil. The pellets have been densified and crystallized by annealing at different peak temperatures resulting in samples with different crystalline phase compositions. For characterization of properties of non-crystallized parent glass (PG), the bulk pieces of the quenched glass frit have been used. The overview of heat treatment performed for manufacturing of different samples is given in Table 1 .

The annealing time has been varied in advance between 0.5 and $5 \mathrm{~h}$. It was found that crystallization of the samples is already completed after $1 \mathrm{~h}$. The preliminary studies showed good reproducibility of sample morphology and impedance spectra for samples of the same composition annealed between 1 and $5 \mathrm{~h}$. For this study, the samples crystallized for $5 \mathrm{~h}$ were used to achieve the conditions closest to equilibrium.

The shrinkage and crystallization of the powder has been analyzed by hot stage dilatometry. Hot stage microscopy (Hesse Instruments, Germany) has been performed by analyzing the changes of the projected and photographed shadows of the sample according to DIN 51,730.
Table 1 Overview of manufactured samples

\begin{tabular}{llll}
\hline Sample & $\begin{array}{l}\text { Heating rate }(\mathrm{K} \\
\left.\mathrm{min}^{-1}\right)\end{array}$ & $\begin{array}{l}\text { Annealing } \\
\text { temperature }\left({ }^{\circ} \mathrm{C}\right)\end{array}$ & $\begin{array}{l}\text { Annealing } \\
\text { time }(\mathrm{h})\end{array}$ \\
\hline S70 & 5 & 700 & 5 \\
S80 & 5 & 800 & 5 \\
S90 & 5 & 900 & 5 \\
S100 & 5 & 1000 & 5 \\
S110 & 5 & 1100 & 5 \\
\hline
\end{tabular}

This method is well described by Pascual and Durán [35]. The calorimetric analysis was performed in differential scanning calorimeter (DSC 404 F1, Netzsch Gerätebau $\mathrm{GmbH}$ ) up to $1100{ }^{\circ} \mathrm{C}$ under synthetic air and analyzed with software Proteus 5.2.0. The heating rate was set to $5 \mathrm{~K} \mathrm{~min}^{-1}$ for both hot stage microscopy and differential thermal analysis (DTA).

Samples for the ionic conductivity (by electrochemical impedance spectroscopy (EIS)) and density measurements have been sputtered with gold (acting as ion blocking electrodes) and pressed between two platinum current collectors. Impedance measurements at room temperature were carried out by a Gamry Reference 600 impedance analyzer with a voltage peak-to-peak amplitude of $\pm 100 \mathrm{mV}$ in a frequency range between $100 \mathrm{kHz}$ and $0.02 \mathrm{~Hz}$. The impedance spectra were evaluated using RelaxIS Software ver. 3.0.17.10 from RHD GmbH.

Density measurements were performed by the Archimedean principle in ethanol with a Sartorius CP2245 balance and a density determination kit. The theoretical density of the fully crystallized material was measured from milled samples by helium pycnometry.

For the quantitative XRD analysis, powder compacts were heat treated under the same conditions as the ones used for impedance measurements. Afterwards, the samples were grinded down to particle size $<63 \mu \mathrm{m}$ and mixed with $33.333 \mathrm{wt} . \%$ pure Si powder as internal reference for calculation of the amorphous phase content. The diffractograms were recorded by a X-ray-diffractometer (D8 Advance, Bruker AXS) with $\mathrm{Cu} \mathrm{K}_{\alpha}$-radiation and a LynxEye position sensitive detector (PSD). The samples were measured in a range of $10-90^{\circ}(2 \theta)$, with a step width of $0.03^{\circ}(2 \theta)$ and a measuring time of $3 \mathrm{~s}$ (PSD). For quantification of the phase fraction, the software TOPAS (V5, Bruker AXS) was used. The structural data for the N3 (ICSD 20,774), N5 (ICSD 166624), and N8 (ICSD 419479) phases were taken from the ICSD database. The error of the values determined for the crystalline phases is limited to $0.6 \mathrm{wt} . \%$ and for the residual amorphous phase $3.0 \mathrm{wt} . \%$. The qualitative analysis was performed with the software DIFFRAC.EVA (Version 4.2., Ltd., Bruker AXS) with an ICDD PDF-2 2015 database.

Microstructural analysis of the microstructures was performed with polished cross-sectioned samples using 
Fig. 1 DSC (dashed line) vs. dilatometry measurement/ shrinkage for NAPSY powder showing temperature ranges for densification $\left(600-680^{\circ} \mathrm{C}\right)$ and crystallization $\left(700^{\circ} \mathrm{C}\right)$

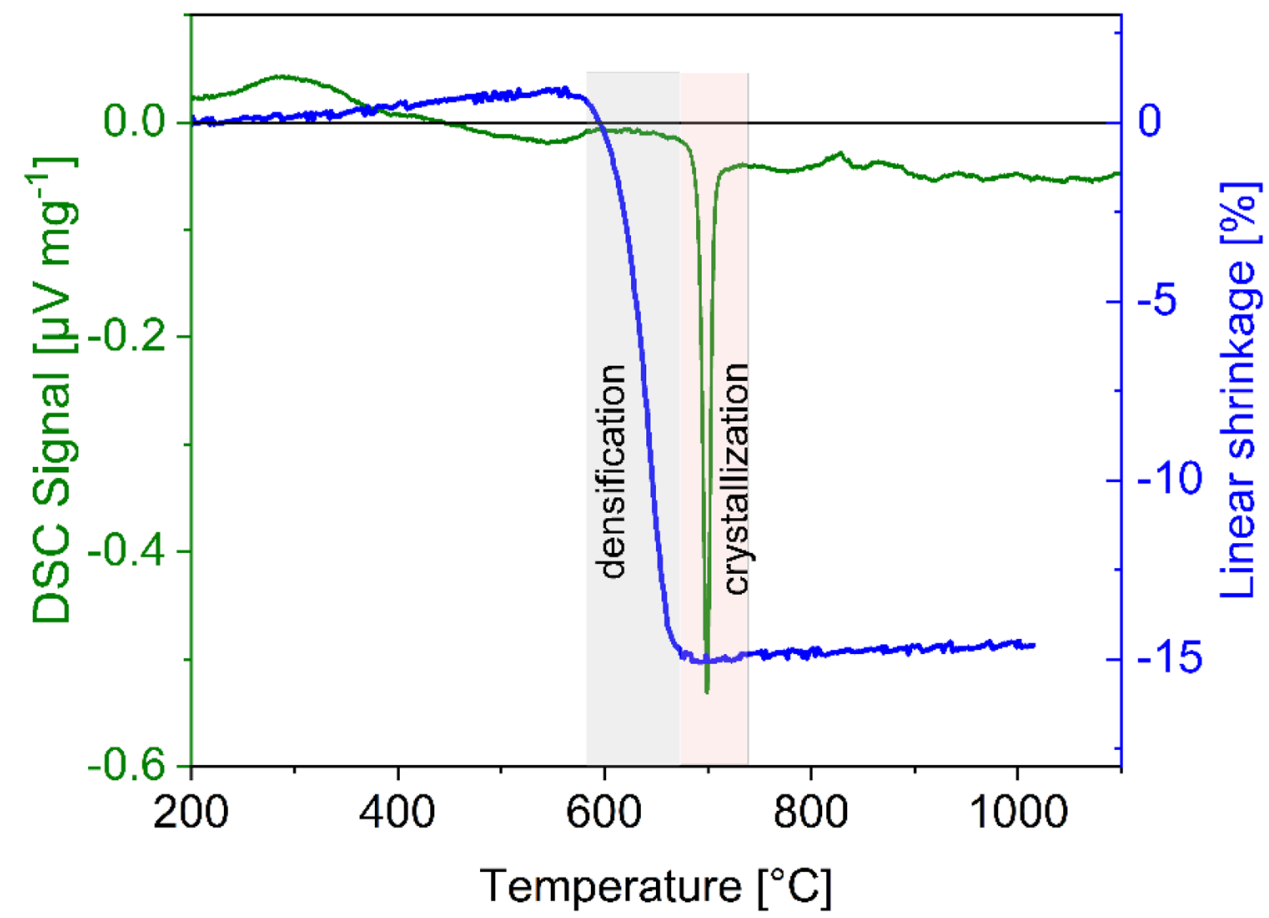

a field emission scanning electron microscope (FE-SEM, NVision 40; Carl Zeiss SMT, Oberkochen, Germany). For the preparation of the samples, a combination of mechanical grinding steps and final ion-polishing by argon-ions was used (RS 101, Bal-Tec, Liechtenstein). The micrographs shown in this paper were recorded in the atomicnumber-specific back-scattered electron (BSE) contrast. The FE-SEM is equipped with an energy-dispersive $\mathrm{X}$-ray analysis system (Inca X-sight; Oxford Instruments, Abingdon, UK), which allows a quantitative detection of elements.

\section{Results and discussion}

\section{Crystallization, phase content, and porosity}

During thermal treatment, NAPSY specimens undergo densification and crystallization processes. The shrinkage and DSC analysis of pelletized samples are shown in Fig. 1. The samples were heated with $5 \mathrm{~K} \mathrm{~min}^{-1}$ up to peak temperature with an annealing time of $5 \mathrm{~h}$.

The linear shrinkage curve reveals that the densification of amorphous powders is completed at $680{ }^{\circ} \mathrm{C}$. The
Fig. 2 XRD patterns of crystallized samples sintered at different temperatures and comparison with PDF cards of the N3 and N5 phases. The content of N5 phase increases with increasing the annealing temperature

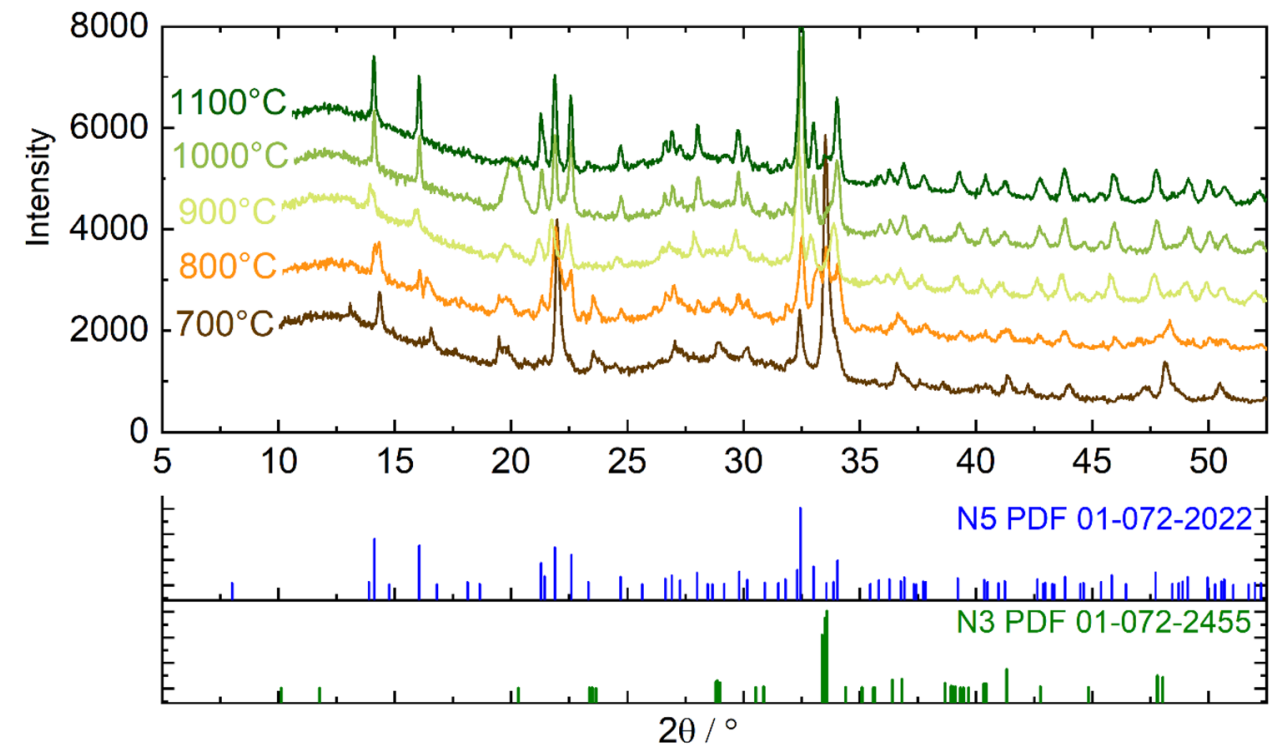


Table 2 Content of N3, N8, and N5 phases obtained by Rietveld refinement of XRD patterns as well as density of sintered samples, porosity, and residual glass phase content in the sintered samples

\begin{tabular}{lllllll}
\hline Sample & $\begin{array}{l}\text { Content N5 } \\
(\text { wt.\% })\end{array}$ & $\begin{array}{l}\text { Content N3 } \\
(\text { wt.\% })\end{array}$ & $\begin{array}{l}\text { Content N8 } \\
(\text { wt.\% })\end{array}$ & $\begin{array}{l}\text { Density (g } \\
\left.\mathrm{cm}^{-3}\right)\end{array}$ & Porosity (\%) & Glass (wt.\%) \\
\hline PG & - & - & - & 2.8 & $<1$ & 100 \\
S70 & 0 & 30 & 14 & 2.37 & 19.8 & 54 \\
S80 & 18 & 23 & 13 & 2.4 & 17.5 & 47 \\
S90 & 60 & 6 & 0 & 2.42 & 15.3 & 34 \\
S100 & 57 & 3 & 0 & 2.48 & 12.9 & 36 \\
S110 & 60 & 7 & 0 & 2.57 & 9.3 & 31 \\
\hline
\end{tabular}

crystallization starts at ca. $700{ }^{\circ} \mathrm{C}$, see DSC curve in Fig. 1, after the maximum shrinkage is achieved. This allows to make crystallization of already densified samples to obtain low porosity levels even at low crystallization temperatures.

XRD patterns of samples crystallized at different temperatures are shown in Fig. 2 together with PDF cards of the $\mathrm{N} 3$ and N5 phases. The phase content of N3 (Na3YSi3O9), N8 (Na8.1YSi6O18), and N5 (Na5YSi4O12) obtained from Rietveld refinement of the XRD patterns is given in Table 2 for each sample subjected to crystallization treatment. Using the method of an internal standard, the residual amorphous phase content is calculated and given in the last column of Table 2.

At $700{ }^{\circ} \mathrm{C}$, the crystallization of $\mathrm{N} 3$ and $\mathrm{N} 8$ phases takes place. Increasing the annealing temperature, reflexes belonging to the $\mathrm{N} 5$ phase appear. Whereas at $800{ }^{\circ} \mathrm{C}$ reflexes of $\mathrm{N} 5$ and $\mathrm{N} 8$ phase are present, at $900{ }^{\circ} \mathrm{C} \mathrm{N} 8$-phase reflexes disappear and the $\mathrm{N} 5$ phase prevails in good agreement with observations of Okura [32].

At $900{ }^{\circ} \mathrm{C}$, the maximum content of the N5-type phase is crystallized and the amount of non-conducting N3 phase is significantly reduced. These investigations show that the major fraction of the crystallized material for samples $\mathrm{S} 90$, S100, and S1 10 consists of N5 phase. The observed formation of the conductive phase of N5-type in NAPSY samples produced via powder route is in a good agreement with observed kinetics of phase formation during the crystallization of NAPSY bulk glasses reported in the literature [31].
As the sintering temperature is increased, the pycnometric density of the samples increases continuously from 80 to $91 \%$ of its pycnometric value. The observed densification is in good agreement with relative densities $85-93 \%$ obtained by Yamashita et al. [36] at sintering temperatures between 920 and $1020{ }^{\circ} \mathrm{C}$ for various $\mathrm{P}_{2} \mathrm{O}_{5}$-containing compositions, however with the non-conducting N3 phase being essentially the main component [30].

Using the values for the content of crystalline phases in wt.\%, their densities $\left(2.96 \mathrm{~g} \mathrm{~cm}^{-3}\right.$ for $\mathrm{N} 3,2.56 \mathrm{~g} \mathrm{~cm}^{-3}$ for $\mathrm{N} 5$, and $2.91 \mathrm{~g} \mathrm{~cm}^{-3}$ for $\mathrm{N} 8$ ) and porosity from Table 2, the residual glass phase volume content is calculated. The determined volume content of all constituents is summarized in Table 3.

\section{Microstructure analysis}

The qualitative crystallization kinetics of glass particles can be resolved by observation of the microstructure of samples sintered at $700{ }^{\circ} \mathrm{C}$ (see Fig. 3). The crystallization front starts from the surface of glass particles and propagates into the center. For this reason, it can be expected that a crystalline phase is first formed on the particle surface, followed by the formation of a grain boundary (GB) between the particles. For the $\mathrm{S} 70$ sample, the crystalline phases are still embedded in a residual glass matrix and the material is composed of glass particles with the embedded crystalline phases.
Table 3 Volume content of all phases present in the microstructure; $x_{G}$ has been calculated using the volume fractions of the phases and sample porosity

\begin{tabular}{lccccc}
\hline Sample & $\begin{array}{l}\text { Content N5 } \\
\left(x_{\mathrm{N} 5}, \%\right)\end{array}$ & $\begin{array}{l}\text { Content N3 } \\
\left(x_{\mathrm{N} 3}, \%\right)\end{array}$ & $\begin{array}{l}\text { Content N8 } \\
\left(x_{\mathrm{N} 8}, \%\right)\end{array}$ & Porosity $\left(x_{\mathrm{P}}, \%\right)$ & Glass $\left(x_{\mathrm{G}}, \%\right)$ \\
\hline PG & - & - & - & - & 100 \\
S70 & - & 24.0 & 11.4 & 19.8 & 44.7 \\
S80 & 16.9 & 18.6 & 10.7 & 17.5 & 36.3 \\
S90 & 56.7 & 4.9 & - & 15.3 & 23.1 \\
S100 & 55.2 & 2.5 & - & 12.9 & 29.4 \\
S110 & 60.2 & 6.1 & - & 9.3 & 24.3 \\
\hline
\end{tabular}

The percolation threshold of the N5 phase is reached starting from $800{ }^{\circ} \mathrm{C}$ (content higher than threshold value of ca. $15 \mathrm{vol} . \%$ is needed for formation of conducting pathways). From $900{ }^{\circ} \mathrm{C}$, the volume content of $\mathrm{N} 5$ phase is greater than $55 \mathrm{vol} . \%$ forming the ionically conducting backbone of glass ceramic composite 
Fig. 3 Results of SEM analysis: surface-initiated crystallization process of $\mathrm{N} 3$ and $\mathrm{N} 8$ phases. After $5 \mathrm{~h}$ of annealing at $700{ }^{\circ} \mathrm{C}$, the non-crystallized residual glass phase stays in the center of the particle
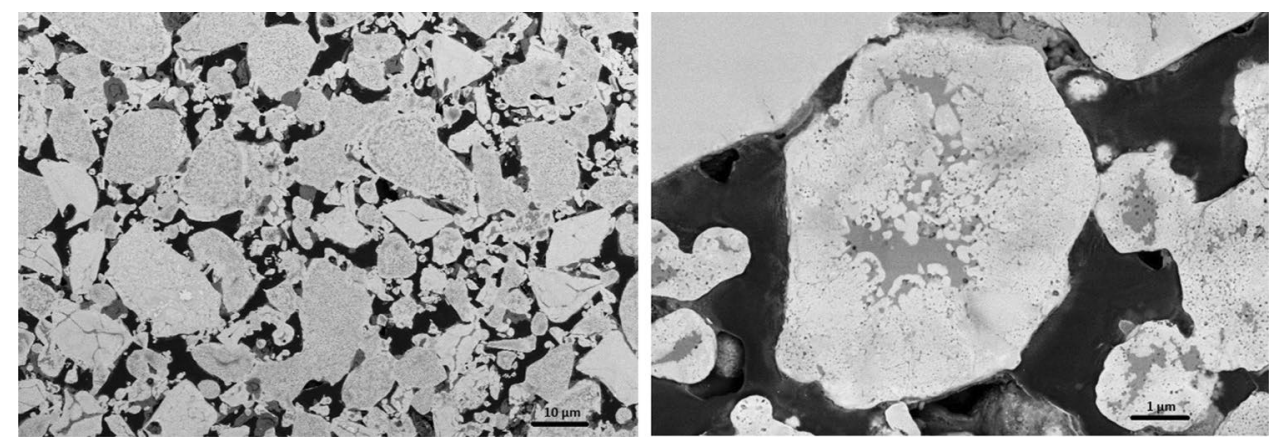

The micrographs of samples sintered at $800{ }^{\circ} \mathrm{C}, 900{ }^{\circ} \mathrm{C}$, $1000^{\circ} \mathrm{C}$, and $1100^{\circ} \mathrm{C}$ are shown in Fig. 4. The visual distinction of individual components (N3 (bright), N5 (gray), and glass phase (dark gray) as well as pores (black) of the microstructure is possible in back scattering electron (BSE) mode imaging. The example of phase analysis by EDX (Fig. 5) shows identification of phases of different grey scale. The results of elemental EDX spot analysis unfortunately cannot provide the precise composition of crystallized phases. Semi-quantitative analysis was used for estimation of sodium, silicon, and yttrium content in different areas of microstructure of crystallized S110 sample to be able to separate N3 (Na3YSi3O9) and N5 (Na5YSi4O12) phases. Combining these results with results of XRD analysis, showing the presence of N3 and N5 phases (see Table 2), the identification of corresponding crystalline phases in the microstructure was possible. Crystalline phase with higher $\mathrm{Na}: \mathrm{Si}$ and $\mathrm{Na}: \mathrm{Y}$ atomic ratios was identified as N5 phase. Small amount of phosphorus was detected by EDX in crystalline and residual glass phases.

The phosphorus concentration in residual glass phase is higher. The EDX element analysis spot analysis of all phases is affected by integral signals from the overlapping phase regions covered by the spot. The SEM micrographs show a progressive densification of the microstructure with increasing sintering temperature, which is in excellent agreement with the results derived from density measurements. Furthermore, a considerable coarsening of crystallized particles takes place between 1000 and $1100{ }^{\circ} \mathrm{C}$.

Also, at higher annealing temperatures of $1000{ }^{\circ} \mathrm{C}$ and $1100{ }^{\circ} \mathrm{C}$ the increased crystallization of $\mathrm{N} 3$ grains is observed, which is in good agreement with results obtained by Rietveld refinement (see Table 2). The reason
Fig. 4 Micrographs of samples sintered at different temperatures. N3 (white), N5 (hell gray), glass phase (dark gray), and pores (black) can be optically seen in micrographs of samples sintered at $1000{ }^{\circ} \mathrm{C}(\mathbf{c})$ and $1100{ }^{\circ} \mathrm{C}(\mathbf{d})$
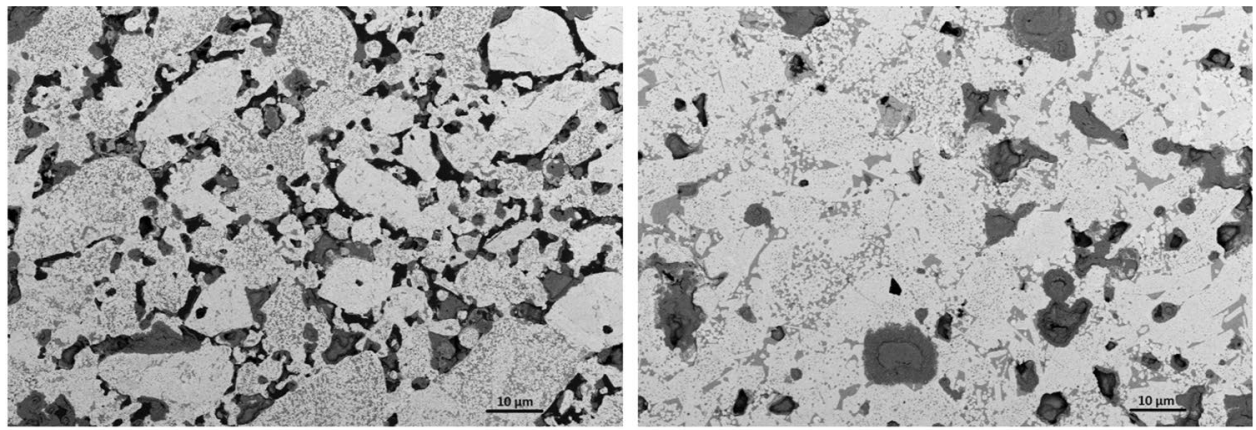

(a) $800^{\circ} \mathrm{C} / 5 \mathrm{~h}$

(b) $900{ }^{\circ} \mathrm{C} / 5 \mathrm{~h}$

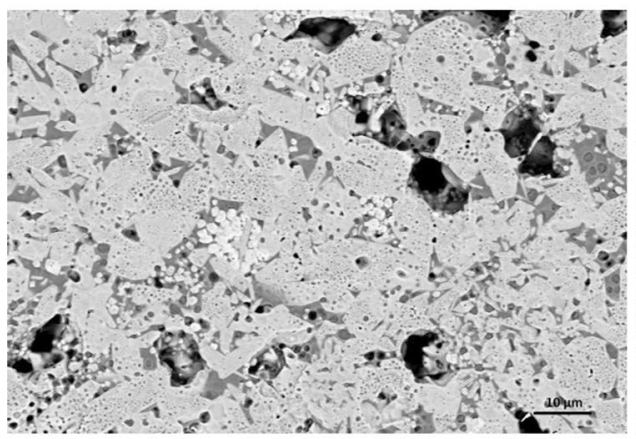

(c) $1000^{\circ} \mathrm{C} / 5 \mathrm{~h}$

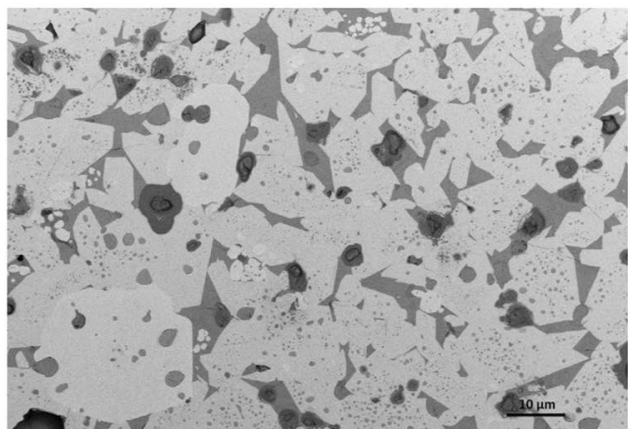

(d) $1100^{\circ} \mathrm{C} / 5 \mathrm{~h}$ 
Fig. 5 Cross section of crystallized NAPSY sample after annealing at $1100^{\circ} \mathrm{C} / 5 \mathrm{~h}$ with emphasized phase mapping

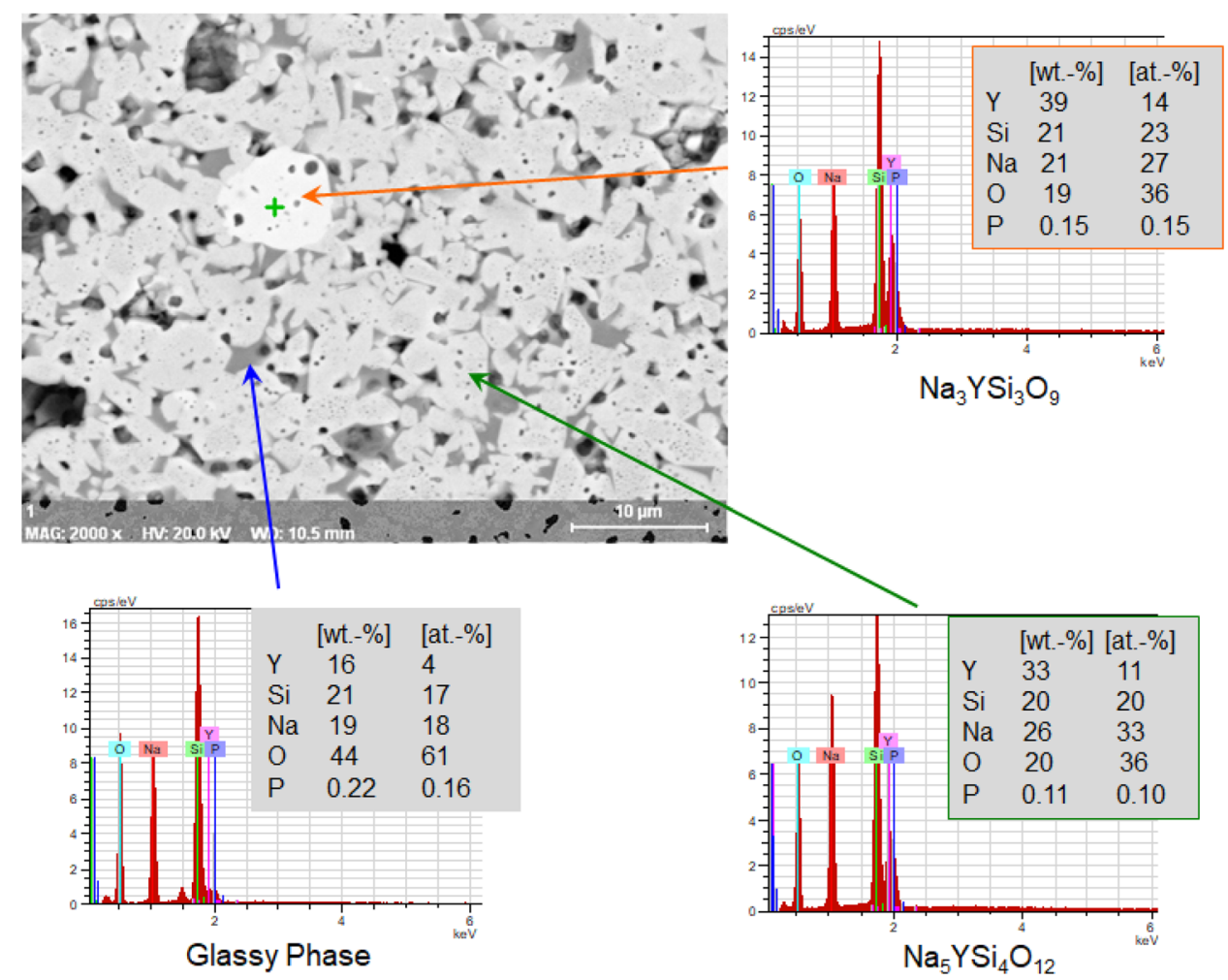

for this behavior is not completely clarified yet. N3 phase contains phosphorus and sodium amounts similar to the residual glass phase and has higher amounts of yttrium (see Fig. 5). In the FE-SEM images, it seems that crystallization of $\mathrm{N} 3$ phase takes place in regions rich in the residual glass phase of the sample. Probably, it is simply a consequence of crystallization of residual glass phase by increasing the temperature. The observed grain growth of N5 particles can be explained by the molten residual glass phase enabling the cation diffusion, crystallization, and "liquid phase" driven coarsening. Simultaneously, the increased presence of large N3-phase particles at high temperatures could be the result of the re-crystallization of N5 particles. The observations of the phase content shift from N5 phase in favor to N3 phase during heat treatment at $1100{ }^{\circ} \mathrm{C}$ indicates that dissolution and crystallization processes occur via residual glass phase at grain boundaries and the wetting of grain boundaries by the glass phase at this temperature is very likely.

\section{Electrochemical impedance spectroscopy}

\section{Spectra analysis}

Figure 6a shows the normalized impedance spectra in the Nyquist representation measured at room temperature for the parent glass (PG) and the sample sintered at $700{ }^{\circ} \mathrm{C}$
(S70, partially crystallized sample with presence of N3 and N8 phase). Both samples show one depressed semi-circle, which can be assigned to the relaxation of charge carriers in the glass phase. Surprisingly, no ion blocking behavior is observed at low frequency, as would be expected at the interface between ionic and electronic conductors with ideal capacity (C) or constant phase element (CPE) with some ohmic losses (high ohmic resistance).

To account for the distribution of relaxation time constants arising from the inhomogeneity of microstructure and material properties like dielectric permittivity and conductivity, a number of (R-CPE) sub-circuits, connected in series, have been used to describe the suppressed grain and grain boundary semi-circles instead of $(\mathrm{R}-\mathrm{C})$ elements. The suppression degree $(\alpha)$ in (R-CPE) circuit is a measure of homogeneity for relaxation time constants (highest homogeneity at $\alpha=1$ ) [37].

At low frequency, non-blocking behavior at the interface PG/gold and S70/gold is observed. This observation indicates no change in type of charge carriers between glass phase and gold electrode. It means that charge transport in isolating glass phase takes place via electrons and not ions. Therefore, the observed high-frequency semi-circle is attributed to electrons hopping rather than to ionic conductivity. It means that transfer number for electrons as charge carriers in glass samples should be higher than that of sodium ions.

Spectra of samples sintered at higher temperatures $\left(900{ }^{\circ} \mathrm{C}, 1000{ }^{\circ} \mathrm{C}\right.$, and $1100{ }^{\circ} \mathrm{C}$, Fig. $6 \mathrm{~b}$ ) show blocking 


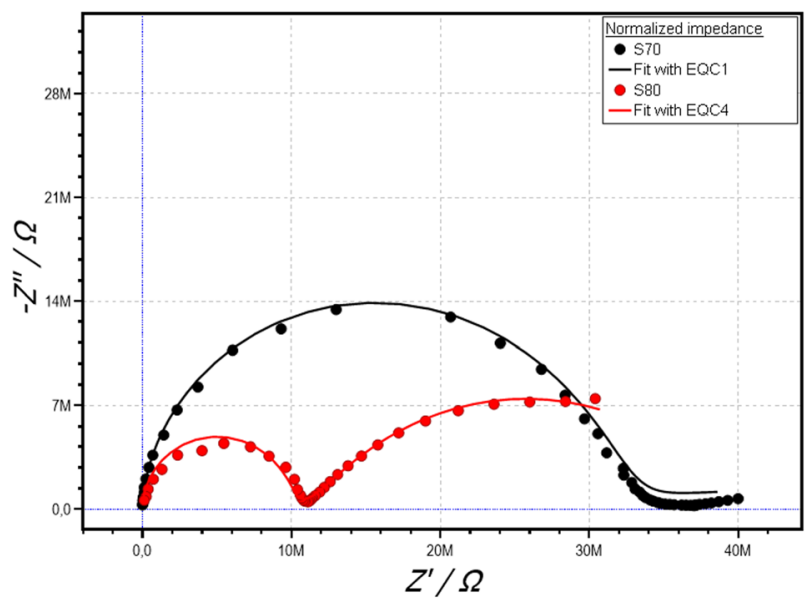

(a)

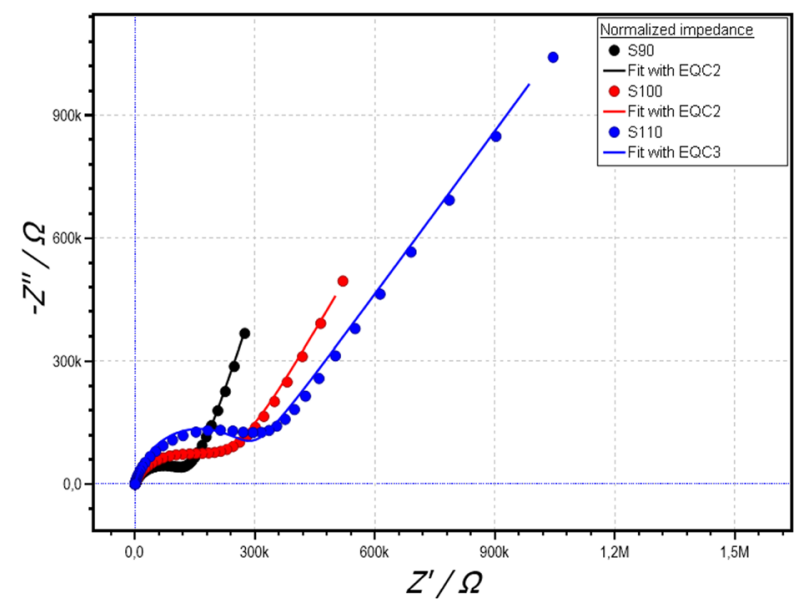

(b)

Fig. 6 Normalized Nyquist plot of sintered samples: raw data and fitted spectra for PG and S70 samples (a) and S90, S100, and S110 samples (b)

interface at low frequencies with slopes $67 \ldots 53^{\circ}$ (higher slopes correspond to lower $\beta$ values in "Sig" element described below), which decrease from S90 to S110 samples. This indicates that crystallization of N5 phase changes the type of conductivity from electronic to ionic one and the electronic conductivity of the residual glass phase has no dominating effect at the interface to the electrode after crystallization. Therefore, the transition from resistive characteristics to a blocking behavior of the interface to the sputtered Au-electrode occurs. For description of the Au-electrode/ crystallized glass interfaces, the conductivity term of Debyetype conductivity response showing power law dependence on frequency defined by Eq. (1) (“Sig”-element of RelaxIS) instead of constant phase element has been used:

$C=\frac{\sigma}{(j \omega)^{\beta}}$

This element results in impedance

$Z=\frac{1}{j \omega C}=\frac{1}{Y_{0}} \frac{1}{(j \omega)^{1-\beta}}$

This type of impedance is mathematically equivalent to CPE with $Q=Y_{0}=\sigma$ and $\alpha=1-\beta$. Differently from CPE element, "Sig" element describes the interface by deviation of its behavior from non-blocking type ( $\beta=1$ corresponds to ideal resistance). For this type of element, low $\beta$-values (close to zero) indicate more capacitive nature of the interface. The physical meaning of frequency-dependent complex dielectric constant and conductivity is given by distribution of energy barriers for charge hopping, which is present at the glass/electronic conductor interface. In this case, the resistance of the interface changes with applied voltage und duration and is not well-defined. In the case of dispersive transport at the interface [38], the charge hopping probability in this case can be a slowly decaying function of time. Accordingly, the process becomes time dependent resulting in a power law dependence on frequency in impedance spectra [38]. For blocking interface ionic conductor/gold the double-layer capacitance (so-called Helmholtz capacitance) can be expected. Also, in case of ionic conductor/gold interface some timely dependent charge hopping cannot be excluded which would also result in some deviation from ideal capacitance behavior.

The shape of the Nyquist plots changes with progressing crystallization and shows at least two semi-circles, which are commonly assigned to grain (N5 grains) and grain boundary (between N5 grains) ionic conductivity. The presence of several phases in the microstructure (see Table 2) does not allow such a simplified interpretation and more detailed analysis of spectra and their correlation with microstructure and identified phase content needs to be performed.

The necessary condition for thorough spectra analysis is the good quality of measured data. The validity of measured EIS was proven by linear Kramers-Kronig transformation, linking real and imaginary part of impedance spectra by transformation function implemented in RelaxIS software for quick check for spectra quality. By Kramers-Kronig transformation the imaginary part of the impedance, $Z$ ', is computed from the real part, $Z$ '. The calculated pseudo- $\chi^{2}$ values from KK test for analysed spectra was in the range $10^{-3}-10^{-4}$. The residuals between measured and calculated imaginary part of the impedance spectra are in sufficient agreement to allow the indicative analysis using distribution of relaxation times (DRT) and appropriate equivalent circuit (EQC) modeling. 


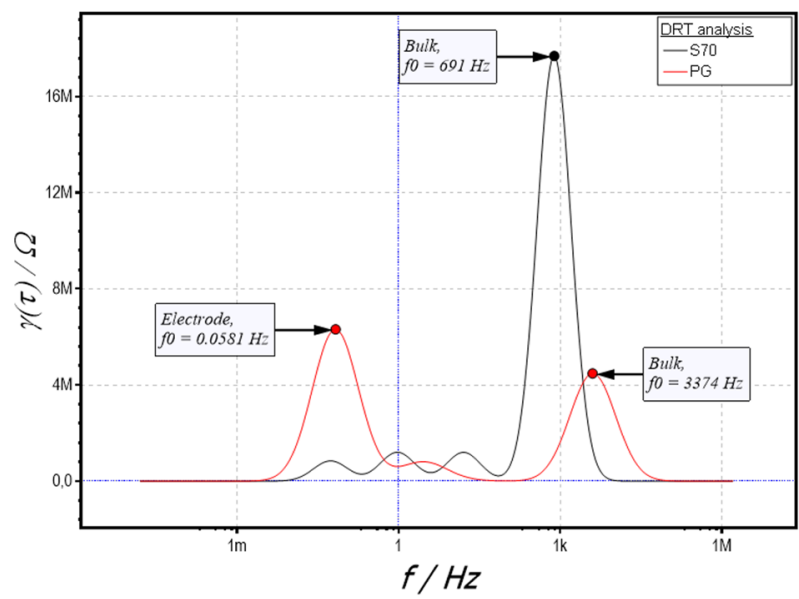

(a)

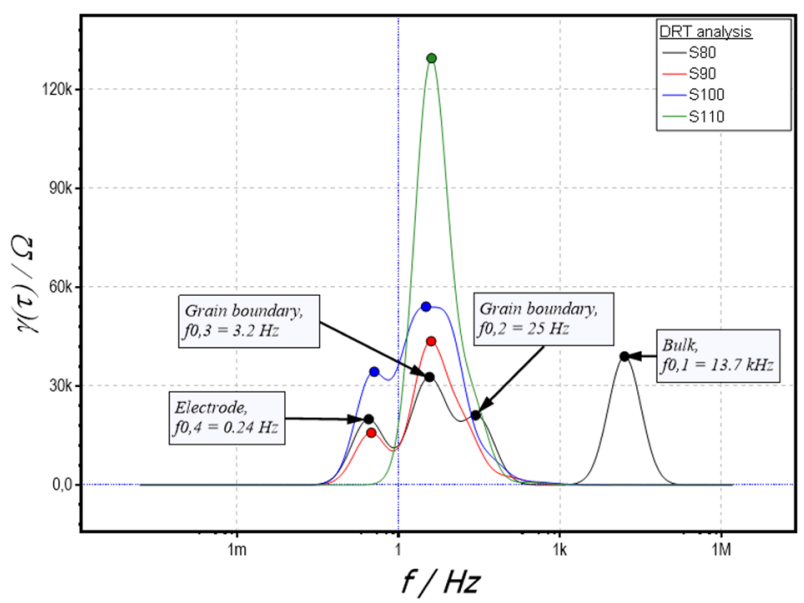

(b)

Fig. 7 DRT analysis of impedance spectra from Fig. 6: (a) DRT of PG and S70 spectra and (b) DRT of S80, S90, S100, and S110 spectra

\section{DRT and EQC}

Impedance spectra in Fig. 6 contain contributions of different phases, which have to be identified by linking the characteristic relaxation frequencies $\left(f_{0}\right)$, microstructure, and XRD analysis. To identify the number of relaxation processes contributing to the impedance of samples sintered at different temperatures, DRT analysis has been performed. Figure 7 a shows the relaxation frequencies for glass frit sample and glass crystallized at $700{ }^{\circ} \mathrm{C}$. Both spectra show only one relaxation frequency corresponding to the impedance of parent glass (frit sample $\mathrm{PG}, f_{0, \mathrm{PG}}=3374 \mathrm{~Hz}$ ) and partially crystallized glass phase ( sample $\mathrm{S} 70, f_{0, \mathrm{~S} 70}=691 \mathrm{~Hz}$ ). The relaxation frequency of the parent glass is slightly shifted to higher frequencies, which indicates differences in chemical composition. The microstructure of S70 in higher magnification (Fig. 8a, b) clearly shows that crystallized particles are still separated by residual glass phase. Thus, despite multiple crystalline phases present in the sample, the isolating glass phase dominates the overall impedance. Such spectra can be fitted using an equivalent circuit containing a parallel connection of resistance $(R)$ and constant phase element (CPE):

$C P E=\frac{1}{Q} \frac{1}{(j \cdot 2 \pi f)^{\alpha}}$

The relaxation frequency of (R-CPE) circuit is defined by the conductivity $(\sigma)$ and dielectric permittivity $(\varepsilon)$ of corresponding material and is material specific characteristic:

$f_{0}=\frac{\sigma}{2 \pi \varepsilon \varepsilon_{0}}$
The suppression degree $(\alpha)$ in (R-CPE) circuit is the measure of homogeneity for relaxation times distribution resulting from distribution of materials properties like dielectric permittivity and conductivity (highest homogeneity at $\alpha=1$; usual range $0.8-0.95$ ) [37].

The estimation of conductivity and dielectric constant of grains and grain boundaries from measured data using equivalent circuit (EQC) analysis is discussed in detail below.

Figure $7 \mathrm{~b}$ shows the DRT analysis of S80, S90, S100 and S110 samples. DRT's are calculated with the RelaxIS software, which follows the Tikhonov regularization method analyzed in detail by the Ciucci et al. [39, 40]. S80 sample, containing $\mathrm{N} 3, \mathrm{~N} 5$, and $\mathrm{N} 8$ crystalline phases additionally to the residual glass phase, shows four distinct relaxation frequencies $\left(f_{0,1}=13.7 \mathrm{kHz}, f_{0,2}=25 \mathrm{~Hz}, f_{0,3}=3.2 \mathrm{~Hz}\right.$, $f_{0,4}=0.24 \mathrm{~Hz}$ ). The microstructure of $\mathrm{S} 80$ in higher magnification is shown in Fig. 8c and d.

The microstructure of the sample contains well-crystallized particles as well as particles containing small crystalline phases separated by glass phase. As far as ionic conducting of fully crystallized N5 phase has the highest relaxation frequency, which is far beyond $100 \mathrm{kHz}$ [34], it can be initially assumed that the frequencies correspond to $\mathrm{N} 8, \mathrm{~N} 3$, and residual glass phase. Increasing the sintering temperature, only two relaxation frequencies are present in the spectra. Thus, it can be assumed that the peak at $f_{0,2}=25 \mathrm{~Hz}$ corresponds to the secondary crystalline phase at grain boundaries, which disappears due to dissolution in residual glass phase with increasing the annealing temperature. Because the DRT conversion has been performed with algorithm including subtraction of electrode contribution, the peaks at lowest frequency can result from the undefined overlap of grain boundary impedance responses with electrode impedance. The splitting of low frequency response 
Fig. 8 Micrographs of samples sintered at 700 (S70) and $800{ }^{\circ} \mathrm{C}(\mathrm{S} 80)$ at higher magnification: (a) $700{ }^{\circ} \mathrm{C} / 5 \mathrm{~h}(\times 3.000)$, (b) $700{ }^{\circ} \mathrm{C} / 5 \mathrm{~h}(\times 10.000)$, (c) $800{ }^{\circ} \mathrm{C} / 5 \mathrm{~h}(\times 5.000)$, and $(\mathbf{d})$ $800{ }^{\circ} \mathrm{C} / 5 \mathrm{~h}(\times 10.000)$

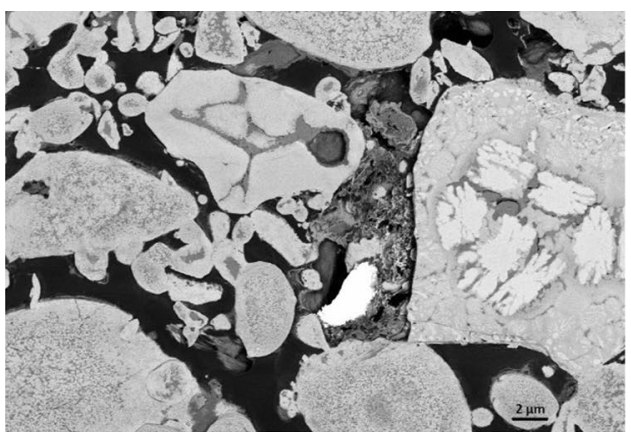

(a)

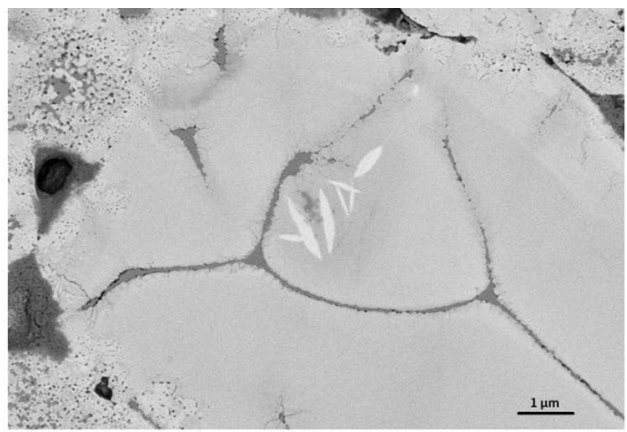

(b)

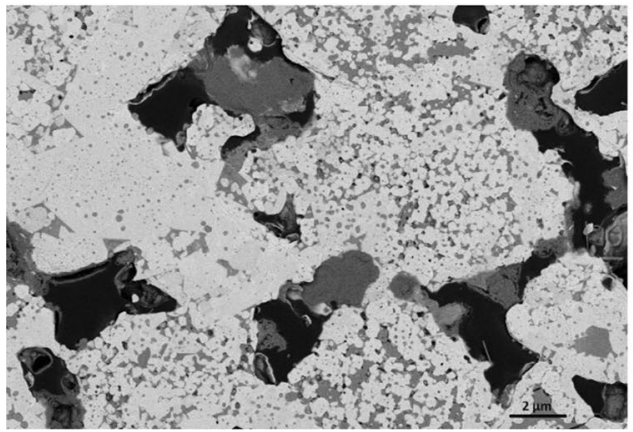

(c)

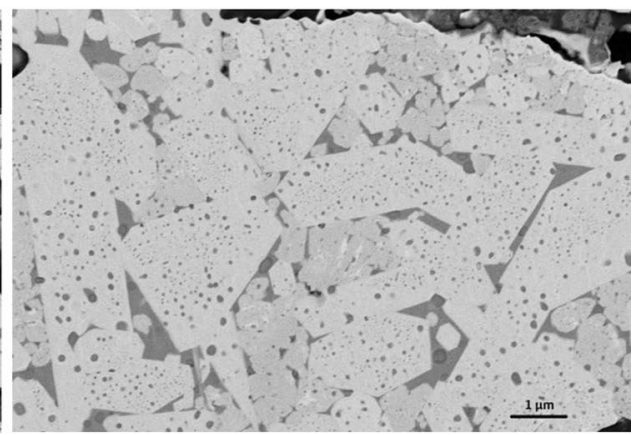

(d) in two characteristic relaxation frequencies $\left(f_{0,3}=3.2 \mathrm{~Hz}\right.$ and $f_{0,4}=0.24 \mathrm{~Hz}$ ) and their nature are analyzed by evaluating spectra with suitable EQC providing improved separation of different contributions. As the relaxation frequency at $f_{0,1}=13.7 \mathrm{kHz}$ disappears in S90 sample, this peak is attributed to N8 phase, which re-crystallizes to ionic conducting N5 phase, or to N5 phase with lower ionic conductivity. At highest sintering temperature the wetting of grain boundaries with glass phase has been deduced. The wetting of grain boundaries by residual glass phase leads to the increase of grain boundary impedance in S100 and S110 and higher contribution of grain boundaries to overall low frequency impedance (impact of the electrode impedance becomes smaller and its subtraction has less influence on result of DRT analysis).

For this reason, the relaxation frequency of this peak $\left(f_{0,3}=f_{0, \mathrm{G}}=3.2 \mathrm{~Hz}\right)$ is attributed to residual glass at grain boundaries and the unidentified peak $f_{0,4}=f_{0, \mathrm{~N} 3}=24 \mathrm{~Hz}$ to crystallized N3 phase at grain boundaries.
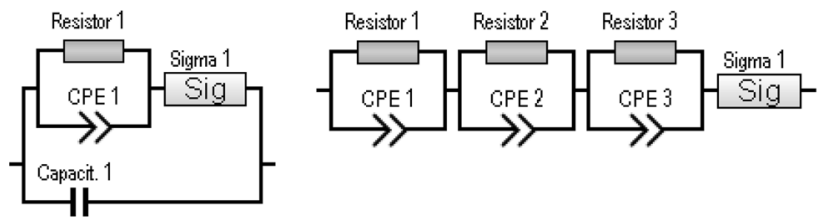

(b)
The results of DRT analysis allow to propose EQC for fitting the impedance spectra, which are shown in Fig. 9. For S70 sample, with very high isolation resistance, the fixed parasitic capacitance of $5 \mathrm{pF}$ (C1 in EQC1) resulting from cables/test fixture has been used to get reasonable results.

\section{Fit results and their interpretation}

The fit results for impedance spectra of all samples are shown in Table 4. Spectrum of S70 sample is fitted with EQC1, spectra S80, S90, and S100 with EQC2, spectrum of S110 with EQC3 and spectrum of PG with EQC4 (see Fig. 9).

The quality of spectra is shown on example of S80 sample in Fig. 10. The relative uncertainties of R1 and Q1, R2 and Q2 and $\sigma$-value from "Sig" element, determined by fitting the EIS data for S80 are less than 5\%.

The conductivity of singular phases can be calculated from fitted normalized values using their volume content from
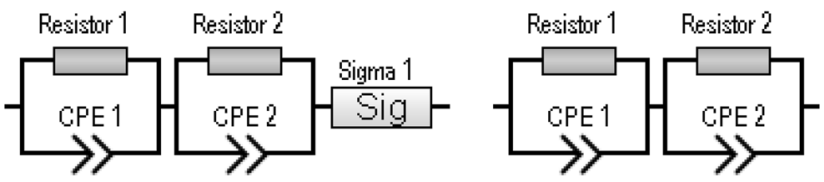

(c)

(d)

Fig. 9 Indicative equivalent circuits EQC1 (a), EQC2 (b), EQC3 (c), and EQC4 (d) used for fitting of impedance spectra of different samples according to the identified electrode contributions and relaxation frequencies from DRT analysis 
Table 4 Fitted results for impedance spectra of all samples

\begin{tabular}{|c|c|c|c|c|c|c|c|c|c|c|c|c|}
\hline Type & EQC & $\mathrm{R} 1(\Omega \mathrm{cm})$ & CPE Q1 & $\alpha 1$ & $\mathrm{R} 2(\Omega \mathrm{cm})$ & CPE Q2 & $\alpha 2$ & $\mathrm{R} 3(\Omega \mathrm{cm})$ & CPE Q3 & $\alpha 3$ & $\Sigma\left(\mathrm{S} \mathrm{cm}^{-1}\right)$ & $\beta$ \\
\hline S70 & EQC1 & $1.9410^{7}$ & $1.2510^{-10}$ & 0.60 & $\mathrm{n} / \mathrm{a}$ & $\mathrm{n} / \mathrm{a}$ & $\mathrm{n} / \mathrm{a}$ & $\mathrm{n} / \mathrm{a}$ & $\mathrm{n} / \mathrm{a}$ & $\mathrm{n} / \mathrm{a}$ & $5.7810^{-8}$ & 0.96 \\
\hline S80 & EQC2 & $1.0910^{5}$ & $3.3110^{-10}$ & 0.80 & $6.5110^{4}$ & $3.6410^{-7}$ & 0.80 & $6.8110^{4}$ & $3.0610^{-6}$ & 0.80 & $1.2510^{-5}$ & 0.31 \\
\hline $\mathrm{S} 90$ & EQC2 & $1.2210^{3}$ & $1.1310^{-9}$ & 0.80 & $1.0610^{5}$ & $5.2110^{-7}$ & 0.80 & $4.1910^{4}$ & $1.4610^{-5}$ & 0.80 & $2.2610^{-5}$ & 0.21 \\
\hline S100 & EQC2 & $6.4710^{2}$ & $\mathrm{n} / \mathrm{a}$ & $\mathrm{n} / \mathrm{a}$ & $1.5910^{5}$ & $4.0710^{-7}$ & 0.80 & $7.5310^{4}$ & $7.2210^{-6}$ & 0.80 & $1.1810^{-5}$ & 0.34 \\
\hline S110 & EQC3 & $4.6910^{2}$ & $\mathrm{n} / \mathrm{a}$ & $\mathrm{n} / \mathrm{a}$ & $2.5310^{5}$ & $1.2610^{-7}$ & 0.93 & $\mathrm{n} / \mathrm{a}$ & $\mathrm{n} / \mathrm{a}$ & $\mathrm{n} / \mathrm{a}$ & $4.1910^{-6}$ & 0.41 \\
\hline PG & EQC4 & $1.0710^{7}$ & $1.0310^{-11}$ & 0.90 & $\mathrm{n} / \mathrm{a}$ & $\mathrm{n} / \mathrm{a}$ & $\mathrm{n} / \mathrm{a}$ & $3.1910^{7}$ & $9.6710^{-8}$ & 0.56 & $\mathrm{n} / \mathrm{a}$ & $\mathrm{n} / \mathrm{a}$ \\
\hline
\end{tabular}

Table $3\left(x_{\mathrm{i}}\right)$ and tortuosity factor $\left(\tau_{\mathrm{i}}\right)$ describing the elongation of diffusion path through the sample:

$\sigma_{i}=\left(x_{i} \tau_{i} R_{i}\right)^{-1}$

For well densified and crystallized sample S110 consisting of 65.6 vol.\% of N5 phase, the tortuosity of 1.4 can be assumed in analogy to values got by $3 \mathrm{D}$ reconstruction for single phase materials [41, 42]. Similarly, the conductivity of parent glass (dense sample from the melt) and crystallized glass (S70, volume content of $85 \%$ and assumed tortuosity 1.15) can be estimated. Sample S80 contains 19.7 vol.\% of N5 phase, the tortuosity factor of which cannot be estimated due to multiple phases present in the sample (values in the range up to 50 has been reported for multicomponent systems [41]). Utilizing the relaxation frequency calculated for $\mathrm{CPE}$ according equation for capacitance $(C)$ and $f_{0}$ calculation from (R-CPE) circuit given by Brug [43]:

$$
\begin{aligned}
& f_{0, i}=\left(2 \pi R_{i} C_{i}\right)^{-1}=\left(2 \pi \sqrt[\alpha]{R_{i} \cdot Q_{i}}\right)^{-1} \\
& C_{i}=\sqrt[\alpha]{R_{i} \cdot Q_{i}} / R_{i}
\end{aligned}
$$

The dielectric constant $\varepsilon_{i}$ of corresponding phase can be obtained, if the relaxation frequency is known:

$\varepsilon_{i}=\sigma_{i} / 2 \pi f_{0, i} \varepsilon_{0}$

The relaxation frequency of fully crystallized N5 phase has been determined by Wagner in frame of her $\mathrm{PhD}$ (to be published) from EIS measurements up to $100 \mathrm{MHz}$ and the obtained $Q$ and $\alpha$ value from corresponding (R1-CPE1) for samples sintered at $1100{ }^{\circ} \mathrm{C}$ showing the same normalized specific resistance and is used for $\varepsilon_{\mathrm{N} 5}$ estimation.

For estimation of conductivity of grain boundary phase, the dielectric constant of crystallized glass phase (S70) can be assumed as far as difference between calculated $\varepsilon$ values for N5 phase and crystallized glass is small. Furthermore, the scattering of dielectric constant between different nonconducting phases with similar compositions is normally not big and changes in relaxation frequency are mainly caused by scattering of conductivity (electronic or ionic) of grain boundary. This assumption is strongly supported by results obtained in Table 5 for these phases resulting in dielectric constant for grain boundaries $\left(\varepsilon_{\mathrm{GB}}=\varepsilon_{\mathrm{S} 70}\right)$ of 26 . The ionic conductivity of grain boundaries can be easily estimated using this value:
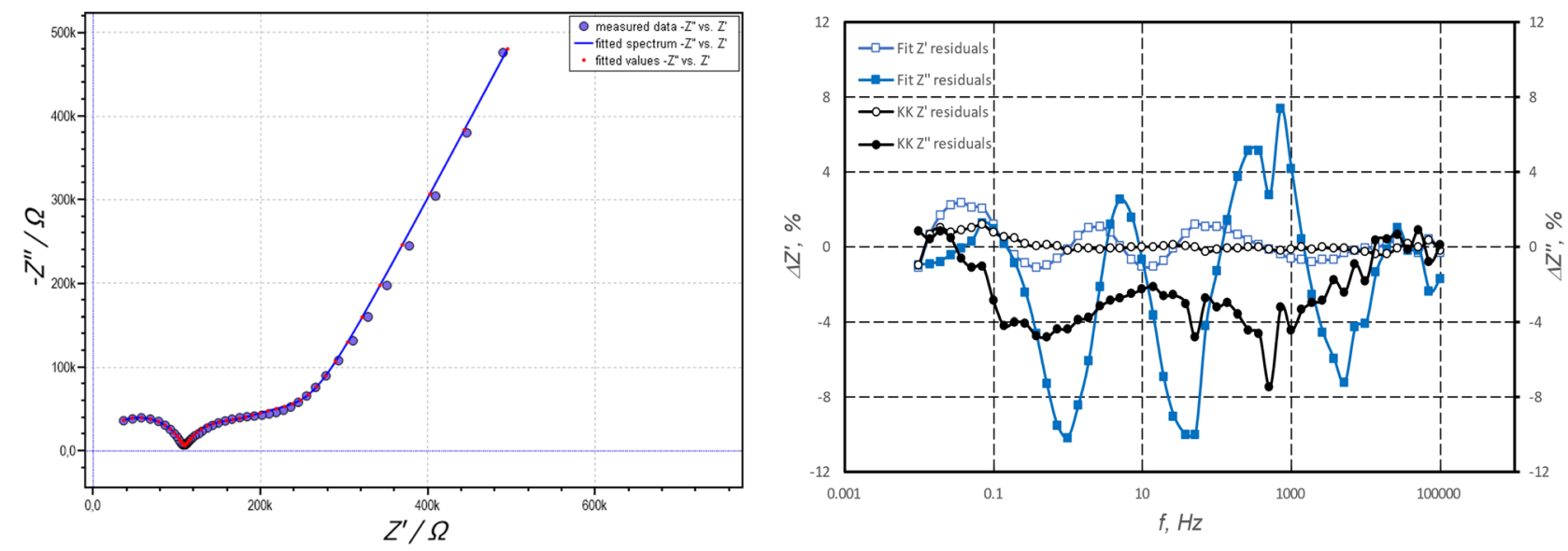

(a)

(b)

Fig. 10 Analysis of EIS for S80 sample: measured data and EQC2 fitted spectra (a) and relative deviations between measured values, KramersKronig (KK) test and fitted values (b) 
Table 5 Estimated electrical properties of different phases at $25^{\circ} \mathrm{C}$

\begin{tabular}{|c|c|c|c|c|c|c|c|c|c|c|}
\hline Phase & Type & $R_{i}(\Omega \mathrm{cm})$ & $Q_{i}$ & $\alpha_{i}$ & $f_{0}(\mathrm{~Hz})$ & $C_{i}\left(\mathrm{~F} \mathrm{~cm}^{-1}\right)$ & $x_{i}(\%)$ & $\tau$ & $\sigma_{i}\left(\mathrm{~S} \mathrm{~cm}^{-1}\right)$ & $\varepsilon$ \\
\hline Parent glass & $\mathrm{e}^{-}$ & $1.0710^{-7}$ & $1.0310^{-11}$ & 0.90 & 4180 & $3.5610^{-12}$ & 1 & 1 & $9.3410^{-8}$ & 40 \\
\hline Crystallized glass (S70) & $\mathrm{e}^{-}$ & $1.9410^{-7}$ & $1.2510^{-10}$ & 0.60 & 3830 & $2.1410^{-12}$ & 0,8 & 1,15 & $5.6010^{-8}$ & 26 \\
\hline $\mathrm{N} 5$ (grain) at $1100^{\circ} \mathrm{C}$ & $\mathrm{Na}^{+}$ & $4.6910^{2}$ & $1.6810^{-10}$ & 0.77 & $2.7510^{8}$ & $1.2410^{-12}$ & 0,55 & 1,4 & $2.7610^{-3}$ & 18 \\
\hline Residual glass $(\mathrm{GB})$ at $1100^{\circ} \mathrm{C}$ & $\mathrm{Na}^{+}$ & $1.5910^{5}$ & $4.0710^{-7}$ & 0.80 & 4.87 & $2.0610^{-7}$ & -- & -- & $7.0410^{-11}$ & 26 \\
\hline Low frequency peak at $900^{\circ} \mathrm{C}$ & $\mathrm{n} / \mathrm{a}$ & $7.5310^{4}$ & $7.2210^{-6}$ & 0.80 & 0.341 & $6.2010^{-6}$ & -- & - & $4.9310^{-12}$ & 26 \\
\hline
\end{tabular}

$\sigma_{G B}=2 \pi f_{0, G B} \varepsilon_{S 70} \varepsilon_{0}$

Calculated conductivities for N5 phase, parent glass and residual glass phase at grain boundaries are summarized in Table 5.

Based on the performed analysis, it is clear that all phases except N5 in this system have very low ionic conductivity. The electronic conductivity of the isolating glass even dominates the total conductivity of non-crystallized samples. The crystallization of $\mathrm{N} 3$ and $\mathrm{N} 8$ in S70 sample increases the total resistance of the parent glass at the same time providing electronic junction to Au-electrodes. This means that electronic conductivity of crystallized phases or residual glass phase is lower than that of the parent glass. Dielectric constant of parent glass, crystallized glass and N5 grain in Table 5 show decreasing values from 40 to 18 . As the difference of dielectric constant between all phases in crystallized glass microstructure is small, only substantial decrease of conductivity of the residual glass phase at grain boundaries would lead to considerable decrease of relaxation frequency in impedance spectra from 3.5 to $0.34 \mathrm{~Hz}$ according Eq. (8). However, Table 4 shows that resistance values for low relaxation frequency arc at $0.3-0.4 \mathrm{~Hz}$ ( $R 3$ values) are much lower in comparison with the resistances for the arc at $3-5 \mathrm{~Hz}$ ( $R 2$ values). Furthermore, for glass frit sample (PG), even lower relaxation frequency of $0.06 \mathrm{~Hz}$ (see Fig. 6a) was observed for the glass/electrode interface. The low frequency arc disappears with increasing crystallinity of the samples, which supports the assumption that low-frequency response can result from glass/Au-electrode interface. The investigations on sintered pre-crystallized powders have also revealed the absence of a low frequency response from electrodes, resulting in pure blocking behavior [34]. For this reason, we attribute this relaxation frequency to double layer capacity between Au-electrode and glass phase. The capacitance values calculated with Eq. (7) and re-normalized to the electrode area of the sample are in good correlation with crystalline $\mathrm{N} 5$ phase content from $3.5 \mu \mathrm{F} \mathrm{cm}$ cm $^{-2}$ for $\mathrm{S} 80$ (16.9 vol.\% N5) to $22 \mu \mathrm{F} \mathrm{cm}^{-2}$ (56.6 vol.\% N5) for S90. Probably (R-CPE) arc at low frequency is built by parallel connection of resistance of electron transfer from residual glass phase to $\mathrm{Au}$-electrode at glass / gold interface (contact nature similar to S70 sample) and double-layer capacitance resulting from interface of N5 grains/gold. The order of magnitude for estimated capacitance is in the range of double layer capacitance between ionic conductor and porous platinum $(\mathrm{Pt})$ electrode reported by Robertson et al. [44].

The decreasing slope of "Sig" element from $67^{\circ}$ to $53^{\circ}$ for S90, S100 and S110 samples (higher slopes correspond to lower conductivity losses and lower $\beta$ values in Table 4) supports the observation that, with increasing the glass content on sample surface, the electrodes show higher ohmic losses and confirm that glass phase builds different interface to Au-electrode in comparison to ionic conducting N5 phase.

\section{Conclusions}

The crystallization and densification behavior of amorphous $\mathrm{Na}_{3+3 x-y} \mathrm{Y}_{1-x} \mathrm{P}_{y} \mathrm{Si}_{3-y} \mathrm{O}_{9}$ powder leads to multiphase microstructure, which has been characterized for different sintering temperatures by XRD, FE-SEM and electrochemical impedance spectroscopy. It was found that parent glass crystallization at $700{ }^{\circ} \mathrm{C}$ leads to the glass embedded nonconducting crystalline N3 and N8 phases. Only crystallization of $\mathrm{N} 5$ phase at higher temperature $\left(\geq 800^{\circ} \mathrm{C}\right)$ provides desired ionic conductivity. The densification takes place before crystallization, which proceeds from the particle surface to its center. The highest content of crystalline phases is reached at $900{ }^{\circ} \mathrm{C}$, resulting in grain boundaries with residual glass phase and $\mathrm{N} 3$ phase. At higher temperature $\left(\geq 1000{ }^{\circ} \mathrm{C}\right.$ ) the wetting of grain boundaries with residual glass phase takes place, which leads to further densification and some dissolution / re-crystallization phenomena at grain boundaries, glass phases, and crystallized particles. The complex analysis of obtained data allows the estimation of the specific conductivity of the N5 phase, which is in the range of $2.8 \mathrm{mS} \mathrm{cm}^{-1}$ at $25^{\circ} \mathrm{C}$ showing great potential for application of this material in SIBs. However, the high conductivity cannot be utilized due to presence of an isolating grain boundary residual glass phase. The mobility of this phase (especially wetting of grain boundaries at higher sintering temperatures) determines the total conductivity of the sample. The contribution of grain boundaries to the total conductivity is difficult to separate from the electrode impedance. To clarify the nature of observed arc in 
impedance spectrum, the thorough analysis of all contributions has been performed. It was found that grain boundaries in this system have relaxation frequency between 3.5 and $5 \mathrm{~Hz}$ and very low ionic conductivity of $0.07 \mathrm{nS} \mathrm{cm}^{-1}$ having a highly isolating impact. The adjustment of powder composition for pre-crystallization of pure highly ionic conducting N5 phase is the topic of ongoing research.

Funding Open Access funding enabled and organized by Projekt DEAL. This work has been supported by the Federal Ministry for the Environment, Nature Conservation and Nuclear safety under the Funding reference number 0325563A and National Research Foundation of Korea (NRF) grant funded by the Korean government (MSIT) (No. 2017H1D8A2031138) and (No. 2020K1A3A1A48111073).

Open Access This article is licensed under a Creative Commons Attribution 4.0 International License, which permits use, sharing, adaptation, distribution and reproduction in any medium or format, as long as you give appropriate credit to the original author(s) and the source, provide a link to the Creative Commons licence, and indicate if changes were made. The images or other third party material in this article are included in the article's Creative Commons licence, unless indicated otherwise in a credit line to the material. If material is not included in the article's Creative Commons licence and your intended use is not permitted by statutory regulation or exceeds the permitted use, you will need to obtain permission directly from the copyright holder. To view a copy of this licence, visit http://creativecommons.org/licenses/by/4.0/.

\section{References}

1. Ierides M, Del Valle R, Fernandez D et al (2019) EMIRI Technology Roadmap, Sept. 2019: Advanced Materials for Clean and Sustainable Energy and Mobility. EMIRI key R\&I priorities

2. Mongrid K, Viswanathan V, Balducci P et al (2019) Energy Storage technology and Cost Characterization Report

3. Li F, Wei Z, Manthiram A et al (2019) Sodium-based batteries: from critical materials to battery systems. J Mater Chem A 7:9406-9431. https://doi.org/10.1039/c8ta11999f

4. Durmus YE, Zhang H, Baakes F et al (2020) Side by Side Battery Technologies with Lithium-Ion Based Batteries. Adv Energy Mater 10:2000089. https://doi.org/10.1002/aenm.202000089

5. Ryu H, Kim T, Kim K et al (2011) Discharge reaction mechanism of room-temperature sodium-sulfur battery with tetra ethylene glycol dimethyl ether liquid electrolyte. J Power Sources 196:5186-5190. https://doi.org/10.1016/j.jpowsour.2011.01.109

6. Kim I, Park J-Y, Kim C et al (2016) Sodium Polysulfides during Charge/Discharge of the Room-Temperature Na/S Battery Using TEGDME Electrolyte. J Electrochem Soc 163:A611-A616. https://doi.org/10.1149/2.0201605jes

7. Kim I, Park J-Y, Kim CH et al (2016) A room temperature $\mathrm{Na} / \mathrm{S}$ battery using a $\beta^{\prime \prime}$ alumina solid electrolyte separator, tetraethylene glycol dimethyl ether electrolyte, and a S/C composite cathode. J Power Sources 301:332-337. https://doi.org/10.1016/j. jpowsour.2015.09.120

8. Yu X, Manthiram A (2014) Room-Temperature Sodium-Sulfur Batteries with Liquid-Phase Sodium Polysulfide Catholytes and Binder-Free Multiwall Carbon Nanotube Fabric Electrodes. J Phys Chem C 118:22952-22959. https://doi.org/10.1021/jp507655u

9. Hwang TH, Jung DS, Kim J-S et al (2013) One-dimensional carbon-sulfur composite fibers for Na-S rechargeable batteries operating at room temperature. Nano Lett 13:4532-4538. https:// doi.org/10.1021/n1402513x

10. Xin S, Yin Y-X, Guo Y-G et al (2014) A high-energy roomtemperature sodium-sulfur battery. Adv Mater 26:1261-1265. https://doi.org/10.1002/adma.201304126

11. Wei S, Ma L, Hendrickson KE et al (2015) Metal-Sulfur Battery Cathodes Based on PAN-Sulfur Composites. J Am Chem Soc 137:12143-12152. https://doi.org/10.1021/jacs.5b08113

12. Wang Y, Song S, Xu C et al (2019) Development of solid-state electrolytes for sodium-ion battery-A short review. Nano Materials Science 1:91-100. https://doi.org/10.1016/j.nanoms.2019.02. 007

13. Zhao C, Liu L, Qi X et al (2018) Solid-State Sodium Batteries Adv Energy Mater 8:1703012. https://doi.org/10.1002/aenm. 201703012

14. Ma Q, Tietz F (2020) Solid-State Electrolyte Materials for Sodium Batteries: Towards Practical Applications. ChemElectroChem 7:2693-2713. https://doi.org/10.1002/celc.202000164

15. Winter M, Besenhard JO (1999) Wiederaufladbare Batterien Chem Unserer Zeit 33:320-332. https://doi.org/10.1002/ciuz. 19990330603

16. Placke T, Kloepsch R, Dühnen S et al (2017) Lithium ion, lithium metal, and alternative rechargeable battery technologies: the odyssey for high energy density. J Solid State Electrochem 21:19391964. https://doi.org/10.1007/s10008-017-3610-7

17. Albertus P, Babinec S, Litzelman S et al (2018) Status and challenges in enabling the lithium metal electrode for high-energy and low-cost rechargeable batteries. Nat Energy 3:16-21. https://doi. org/10.1038/s41560-017-0047-2

18. Tang WS, Yoshida K, Soloninin AV et al (2016) Stabilizing Superionic-Conducting Structures via Mixed-Anion Solid Solutions of Monocarba- closo -borate Salts. ACS Energy Lett 1:659-664. https://doi.org/10.1021/acsenergylett.6b00310

19. Hayashi A, Masuzawa N, Yubuchi S et al (2019) A sodium-ion sulfide solid electrolyte with unprecedented conductivity at room temperature. Nat Commun 10:5266. https://doi.org/10.1038/ s41467-019-13178-2

20. May GJ, Hooper A (1978) The effect of microstructure and phase composition on the ionic conductivity of magnesium-doped sodium-beta-alumina. J Mater Sci 13:1480-1486. https://doi.org/ 10.1007/BF00553202

21. Ma Q, Tsai C-L, Wei X-K et al (2019) Room temperature demonstration of a sodium superionic conductor with grain conductivity in excess of $0.01 \mathrm{~S} \mathrm{~cm}-1$ and its primary applications in symmetric battery cells. J Mater Chem A 7:7766-7776. https://doi. org/10.1039/C9TA00048H

22. Bentzen JJ, Nicholson PS (1980) The preparation and characterization of dense, highly conductive Na5GdSi4O12 nasicon (NGS). Mater Res Bull 15:1737-1745. https://doi.org/10.1016/ 0025-5408(80)90191-9

23. Patel M, Chandrappa KG, Bhattacharyya AJ (2010) Increasing ionic conductivity of polymer-sodium salt complex by addition of a non-ionic plastic crystal. Solid State Ionics 181:844-848. https://doi.org/10.1016/j.ssi.2010.04.013

24. Manthiram A, Yu X, Wang S (2017) Lithium battery chemistries enabled by solid-state electrolytes. Nat Rev Mater 2. https://doi. org/10.1038/natrevmats.2016.103

25. Fergus JW (2012) Ion transport in sodium ion conducting solid electrolytes. Solid State Ionics 227:102-112. https://doi.org/10. 1016/j.ssi.2012.09.019

26. Fuentes RO, Figueiredo FM, Soares MR et al (2005) Submicrometric NASICON ceramics with improved electrical conductivity obtained from mechanically activated precursors. J Eur Ceram Soc 25:455-462. https://doi.org/10.1016/j.jeurceramsoc.2004.02.019 
27. Shannon RD, Taylor BE, Gier TE et al (1978) Ionic conductivity in sodium yttrium silicon oxide (Na5YSi4O12)-type silicates. Inorg Chem 17:958-964. https://doi.org/10.1021/ic50182a033

28. Okura T, Yamashita K (2020) New Na+ Superionic Conductor Narpsio Glass-Ceramics. In: Onishi T (ed) Theoretical chemistry for advanced nanomaterials: Functional analysis by computation and experiment. Springer, Gateway East, Singapore, pp 383-416

29. Yamashita K, Nicholson P (1985) Spray-drying and fabrication of superionic conducting sodium rare-earth silicates. Solid State Ionics 17:115-120. https://doi.org/10.1016/0167-2738(85)90058-X

30. Yamashita K, Matsuda M, Umegaki T (1998) Synthesis and Na + conduction properties of the ceramics of Na 5 YSi 4 O 12 -type phosphate-substituted solid solutions. J Mater Res 13:3361-3364. https://doi.org/10.1557/JMR.1998.0456

31. Yamashita K, Tanaka M, UMEGAKI T, (1992) Thermodynamic and kinetic study on the phase transformation of the glass-ceramic $\mathrm{Na}+$ superionic conductors $\mathrm{Na} 3+3 \mathrm{x}-\mathrm{yRe} 1-\mathrm{xPySi} 3-\mathrm{yO} 9$ 败. Solid State Ionics 58:231-236. https://doi.org/10.1016/01672738(92)90123-7

32. Okura T (2012) Preparation of Na+ Superionic Conductors by Crystallization of Glass. In: Mastai Y (ed) Advances in Crystallization Processes. INTECH Open Access Publisher

33. Yamashita K (2020) Development of functional inorganic phosphorus materials science. Phosphorus Res Bull 36:1-9. https:// doi.org/10.3363/prb.36.1

34. Wagner D, Schilm J, Lee CW et al (2020) Impact of Precrystallized NaYSi 4 O 12 Powders in the Synthesis of Sodium Conducting Solid Electrolytes. Energy Technol 8:2000559. https://doi.org/ 10.1002/ente.202000559

35. Lara C, Pascual M, Prado $M$ et al (2004) Sintering of glasses in the system $\mathrm{RO}-\mathrm{Al} 2 \mathrm{O} 3-\mathrm{BaO}-\mathrm{SiO} 2(\mathrm{R}=\mathrm{Ca}, \mathrm{Mg}, \mathrm{Zn})$ studied by hot-stage microscopy. Solid State Ionics 170:201-208. https://doi. org/10.1016/j.ssi.2004.03.009

36. Yamashita K, OHKURA S, Umegaki T et al (1988) Synthesis, Polymorphs and Sodium Ionic Conductivity of Sodium Yttrium Silicophosphates with the Composition. J Ceram Soc Japan 96:967-972. https://doi.org/10.2109/jcersj.96.967
37. McNealy BE, Hertz JL (2014) On the use of the constant phase element to understand variation in grain boundary properties. Solid State Ionics 256:52-60. https://doi.org/10.1016/j.ssi.2013. 12.030

38. Barsoukov E, Macdonald JR (eds) (2005) Impedance spectroscopy: Theory, experiment, and applications, 2nd edn. WileyInterscience, Hoboken (New Jersey)

39. Bremm S, Dölling S, Becker W et al (2021) A methodological contribution to failure prediction of glass ceramics sealings in high-temperature solid oxide fuel cell stacks. J Power Sources 507:230301. https://doi.org/10.1016/j.jpowsour.2021.230301

40. Wan TH, Saccoccio M, Chen $C$ et al (2015) Influence of the Discretization Methods on the Distribution of Relaxation Times Deconvolution: Implementing Radial Basis Functions with DRTtools. Electrochim Acta 184:483-499. https://doi.org/10.1016/j. electacta.2015.09.097

41. Joos J (2017) Microstructural Characterisation. KIT Scientific Publishing, Modelling and Simulation of Solid Oxide Fuel Cell Cathodes

42. Yan Z, Hara S, Kim Y et al (2017) Homogeneity and representativeness analyses of solid oxide fuel cell cathode microstructures. Int J Hydrogen Energy 42:30166-30178. https://doi.org/10.1016/j. ijhydene.2017.10.096

43. Brug GJ, van den Eeden A, Sluyters-Rehbach M et al (1984) The analysis of electrode impedances complicated by the presence of a constant phase element. J Electroanal Chem Interfacial Electrochem 176:275-295. https://doi.org/10.1016/S0022-0728(84) 80324-1

44. Robertson NL, Michaels JN (1991) Double Layer Capacitance of Porous Platinum Electrodes in Zirconia Electrochemical Cells. J Electrochem Soc 138:1494-1499. https://doi.org/10.1149/1.2085814

Publisher's Note Springer Nature remains neutral with regard to jurisdictional claims in published maps and institutional affiliations. 